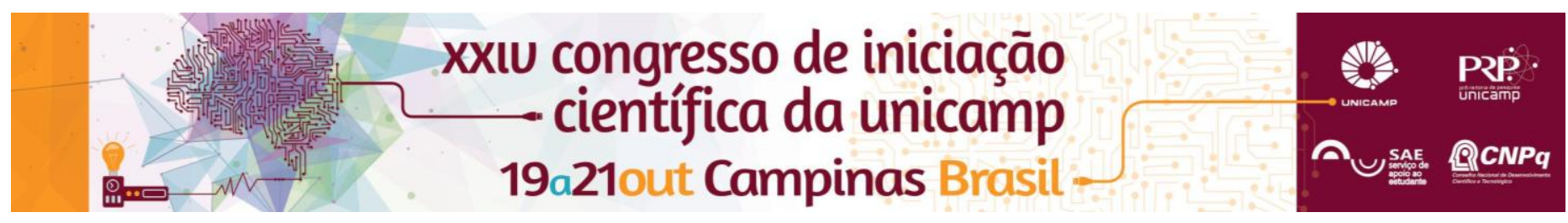

\title{
Isolamento de ácidos húmicos de solos e estudo de suas interações com antimicrobianos de uso veterinário
}

\author{
Isabela H. Sato*, Mónica J. Martínez- Mejía, Susanne Rath.
}

\begin{abstract}
Resumo
Neste trabalho foram avaliadas as interações de fármacos antimicrobianos com ácidos húmicos (HA) extraídos de diferentes solos do estado de São Paulo. Foram utilizadas como moléculas molde os antimicrobianos enrofloxacina (ENR) e sulfaquinoxalina (SQX), pertencentes as famílias das fluoroquinolonas e sulfonamidas, respectivamente. As interações foram estudadas por meio da sorção dos fármacos no HA, utilizando como variáveis as condições do meio como:cátion trocador, $\mathrm{pH}$ e conteúdo de matéria orgânica. A quantificação foi realizada utilizando-se a cromatografia líquida de alta eficiência com detectores de arranjo de fotodiodos e fluorescência. Os HA foram caracterizados por diferentes técnicas analíticas. A ENR interage fortemente com os HA, enquanto a SQX apresenta uma menor afinidade.
\end{abstract}

Palavras-chave:

Ácido húmico, fármacos veterinários, sorção.

\section{Introdução}

O crescimento no mercado agropecuário está unido ao aumento na demanda por uso de medicamentos veterinários, incluindo antimicrobianos.Os fármacos como os metabólitos podem entrar no ambiente mediante a utilização de estrume em terras agrícolas ou devido à deposição direta do animal, representando uma nova fonte de contaminantes persistentes no ambiente ${ }^{1}$. O destino destes antimicrobianos no ambiente depende das propriedades físico químicas do composto e do solo, em particular, do teor de matéria orgânica e composição química dos ácidos húmicos presentes no mesmo.

$\mathrm{Na}$ atualidade, pouca informação se tem sobre a dinâmica dos antimicrobianos em solos brasileiros, cujas características são muito diferentes dos encontrados no hemisfério norte. A fim de contribuir na resolução desta lacuna de informação, este trabalho avaliou a contribuição das substâncias húmicas isoladas de solos brasileiros na sorção e dessorção de antimicrobianos da classe das fluoroquinolonas e sulfonamidas.

\section{Resultados e Discussão}

1. Extração e caracterização dos ácidos húmicos

Foram coletados três solos representativos do estado de São Paulo: Latossolo vermelho (LVe), Latossolo vermelho-amarelo (LVAd) e Neossolo quartzênico (RQo).A extração dos ácidos húmicos do solo foi realizada segundo 0 procedimento descrito pelo $\mathrm{IHSS}^{2}$. O teor de HA dos solos foi de $0,45 \%, 0,44 \%$ e $0,85 \%$ para os solos $R Q$, LVe e LVAd, respectivamente.

Os resultados da análise de espectroscopia de absorção na região UV-Vis dos HA, permitiu determinar que a capacidade de complexação dos HA extraídos segue a ordem RQo < LVAd < LVe.

Os resultados da espectroscopia no IV permitiram adquirir informações a respeito da composição relativa de grupos fenólicos e alcóolicos, carboxílicos, alifáticos e aromáticos dos HA. Cabe ressaltar que o HA extraído do solo LVe se caracteriza por apresentar maior conteúdo de grupos carboxílicos do que os HA do solo LVAd. Por fim, foram realizadas titulações potenciométricas, utilizando o método desenvolvido por Schnitzer e Gupta ${ }^{3}$, a fim de se avaliar a acidez fenólica e carboxílica. A maior acidez carboxílica foi obtida para o HA LVe, enquanto que a maior acidez fenólica foi observada para O HA RQo e LVAd com 5,80 e 3,72 mmol $\mathrm{H}^{+} \mathrm{g}^{-1} \mathrm{HA}$, respectivamente.

\section{Isotermas de sorção dos fármacos antimicrobianos}

Foram desenvolvidos e validados os métodos cromatográficos para a determinação dos fármacos ENR e SQX.

Os ensaios de sorção foram feitos seguindo as diretrizes do Guia OECD $106^{4}$. O cálculo do coeficiente de Freundlich permitiu determinar a alta capacidade de sorção da ENR nos HA dos solos (19534 $\leq \mathrm{K}_{\mathrm{F}} \geq 3918$ ), quando comparado com SQX (1030 $\left.\leq K_{F} \geq 853\right)$, o que corrobora os resultados obtidos nos solos.

A sorção da ENR nos HA é altamente dependente do pH do meio de sorção e da proporção relativa de domínos orgânicos aromáticos e carboxílicos nos mesmos, sendo que a sorção é máxima em $\mathrm{pH} 5$ para o HA do solo LVAd e $\mathrm{pH} 3$ para o solo RQo. Da mesma maneira, foi evidenciado que o HA do solo LVAd tem potencial de interagir com a ENR mediante formação ponte catiônica, facilitado por seus grupos ácido carboxílicos em sua forma aniônica e estabilizado pelos grupos fenólicos.

\section{Conclusões}

Os ensaios de sorção evidenciaram alta afinidade da ENR com matéria orgânica dos solos Brasileiros avaliados. Foi possível identificar diferenças estruturais dos HA chaves no processo de sorção destes fármacos.

\section{Agradecimentos}

Agencias de fomento CNPq e FAPESP (2013/09543-7).

${ }^{1}$ SINDAN, http://www.sindan.org.br/sd/base.aspx?controle=8

${ }^{2}$ IHSS, http://www.humicsubstances.org/soilhafa.html

${ }^{3}$ Prado A. G. S., Souza S. M., Lopes W. T., Rezende M. O. O.Química Nova, 22(6). 1999. 894-896

${ }^{4}$ OECD, Test No. 106: Adsorption - Desorption Using a Batch Equilibrium Method, OECD Publishing, 2000 